\title{
Heme oxygenase-1 and carbon monoxide suppress autoimmune neuroinflammation
}

\author{
Ângelo A. Chora, ${ }^{1}$ Paulo Fontoura, ${ }^{2}$ Andreia Cunha, ${ }^{1}$ Teresa F. Pais, ${ }^{1}$ Sílvia Cardoso, ${ }^{1}$ Peggy P. Ho, ${ }^{3}$ \\ Lowen Y. Lee, ${ }^{3}$ Raymond A. Sobel, ${ }^{4}$ Lawrence Steinman, ${ }^{3}$ and Miguel P. Soares ${ }^{1}$
}

\begin{abstract}
1 Instituto Gulbenkian de Ciência, Oeiras, Portugal. 2Departamento de Imunologia, Faculdade de Ciências Médicas, Universidade Nova de Lisboa, Lisbon, Portugal. ${ }^{3}$ Department of Neurology and Neurological Sciences, Beckman Center for Molecular Medicine, and ${ }^{4}$ Department of Pathology, Stanford University School of Medicine, Stanford, California, USA.
\end{abstract}

\begin{abstract}
Heme oxygenase-1 (HO-1, encoded by HMOX1) dampens inflammatory reactions via the catabolism of heme into $\mathrm{CO}, \mathrm{Fe}$, and biliverdin. We report that expression of HO-1 dictates the pathologic outcome of experimental autoimmune encephalomyelitis (EAE), a model of multiple sclerosis (MS). Induction of EAE in Hmox1 $1^{-/}$

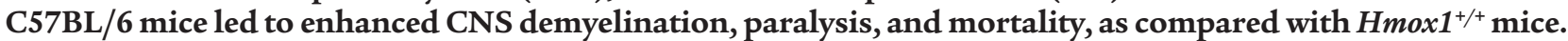
Induction of HO-1 by cobalt protoporphyrin IX (CoPPIX) administration after EAE onset reversed paralysis in $\mathrm{C} 57 \mathrm{BL} / 6$ and $\mathrm{SJL} / \mathrm{J}$ mice and disease relapse in $\mathrm{SJL} / \mathrm{J}$ mice. These effects were not observed using zinc pro-

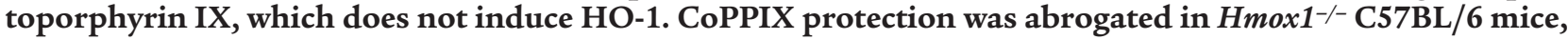
indicating that CoPPIX acts via HO-1 to suppress EAE progression. The protective effect of HO-1 was associated with inhibition of MHC class II expression by APCs and inhibition of Th and CD8 T cell accumulation, proliferation, and effector function within the CNS. Exogenous $\mathrm{CO}$ mimicked these effects, suggesting that $\mathrm{CO}$ contributes to the protective action of $\mathrm{HO}-1$. In conclusion, $\mathrm{HO}-1$ or exposure to its end product $\mathrm{CO}$ counters autoimmune neuroinflammation and thus might be used therapeutically to treat MS.
\end{abstract}

\section{Introduction}

MS is a presumed autoimmune disorder that targets the CNS (1). Neuroinflammatory lesions associated with MS progression are triggered upon interaction of activated pathogenic Th cells with APCs within the CNS. This leads to the generation of a proinflammatory response that causes irreversible oligodendrocyte injury, neuron demyelination, and eventually axonal loss, the main pathologic hallmarks of MS (2-4).

The clinical course of MS is, in most cases, associated with transitory episodes of remission (2), suggesting that regulatory mechanisms must operate to counter neuroinflammation and/or to promote neuron regeneration. Such mechanisms may involve, but are most probably not limited to, the participation of regulatory $\mathrm{T}$ cells $(5,6)$. We hypothesized that expression of "protective genes" $(5,7)$ might also promote MS remission. One candidate is heme oxygenase-1 (HMOX1/HO-1), a prototypical cytoprotective and antiinflammatory stress-responsive gene (reviewed in refs. 5, 8) expressed in the CNS during the course of MS (9) and EAE (10), a well-established model of MS (11).

Under inflammatory conditions, HO-1 becomes the rate-limiting enzyme in the catabolism of heme, yielding equimolar amounts of $\mathrm{CO}$, free $\mathrm{Fe}$, and biliverdin (12), which is subsequently reduced into bilirubin by biliverdin reductase (reviewed in ref. 13). Induction of HO- 1 by metal protoporphyrins has been shown to have salutary effects in a variety of experimental inflammatory conditions (reviewed in refs. 8, 14). The observation that in most cases, exposure to $\mathrm{CO}$ can mimic the protective effects of $\mathrm{HO}-1$ (reviewed

Nonstandard abbreviations used: CIITA, MHC class II transcription activator; CoPPIX, cobalt protoporphyrin IX; HO-1, heme oxygenase-1; M $\phi$, macrophages; $\mathrm{MOG}_{35-55}$, myelin oligodendrocyte glycoprotein peptide 35-55; $\mathrm{PLP}_{139-151}$, proteolipid protein peptide 139-151; ZnPPIX, zinc protoporphyrin IX.

Conflict of interest: The authors have declared that no conflict of interest exists. Citation for this article: J. Clin. Invest. 117:438-447 (2007). doi:10.1172/JCI28844. in refs. 8,15$)$ would suggest that $\mathrm{HO}-1$ acts in a protective manner via the generation of CO. It is likely, however, that other end products of HO-1 activity such as biliverdin (16) and/or free Fe (by upregulating heavy chain ferritin expression, ref. 17; or cellular Fe efflux pumps, ref. 18) may exert similar effects.

Whether HO-1 modulates the pathogenesis of autoimmune neuroinflammation remained to be established, because both protective (19) and deleterious (20) effects of chemical HO-1 modulators have been demonstrated in EAE. Using HO-1-deficient $\left(\mathrm{Hmox1}^{-/-}\right)$mice, we demonstrate that expression of HO-1 inhibited inflammation, demyelination, and paralysis, preventing mortality associated with the development of EAE. We also provide evidence that induction of HO-1 using protoporphyrins modulated ongoing autoimmune neuroinflammation, thereby reverting paralysis and leading to disease remission in mice with previously established EAE. Exogenous CO mimicked this effect, which suggests that this end product of heme degradation contributes to the protective action of HO-1. Suppression of EAE was associated with inhibition of (a) leukocyte accumulation in the CNS, (b) MHC class II expression by CNS APCs, and (c) pathogenic Th cell proliferation and effector function.

\section{Results}

Expression of HO- 1 counters the pathogenesis of EAE. Given that HO-1 expression in the CNS is associated with the development of both EAE and MS $(10,19,20)$, and based on the well-established protective effect of HO-1 (reviewed in refs. 5, 8), we hypothesized that HO-1 might modulate the pathogenesis of EAE. When immunized with the myelin oligodendrocyte glycoprotein peptide 35-55

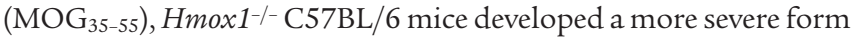
of EAE than did wild-type $\left(H \operatorname{mox} 1^{+/+}\right)$C57BL/6 mice (Figure $1 \mathrm{~A}$ and Table 1), with $75 \%$ mortality in $H$ mox $1^{-1-}$ mice compared with $19 \%$ mortality in $\mathrm{Hmox}^{+/+}$controls $(P=0.0024$; Table 1$)$.

We tested whether induction of $\mathrm{HO}-1$ by metal protoporphyrins would arrest EAE progression in $H \operatorname{mox} 1^{+/+} \mathrm{C} 57 \mathrm{BL} / 6$ mice. 

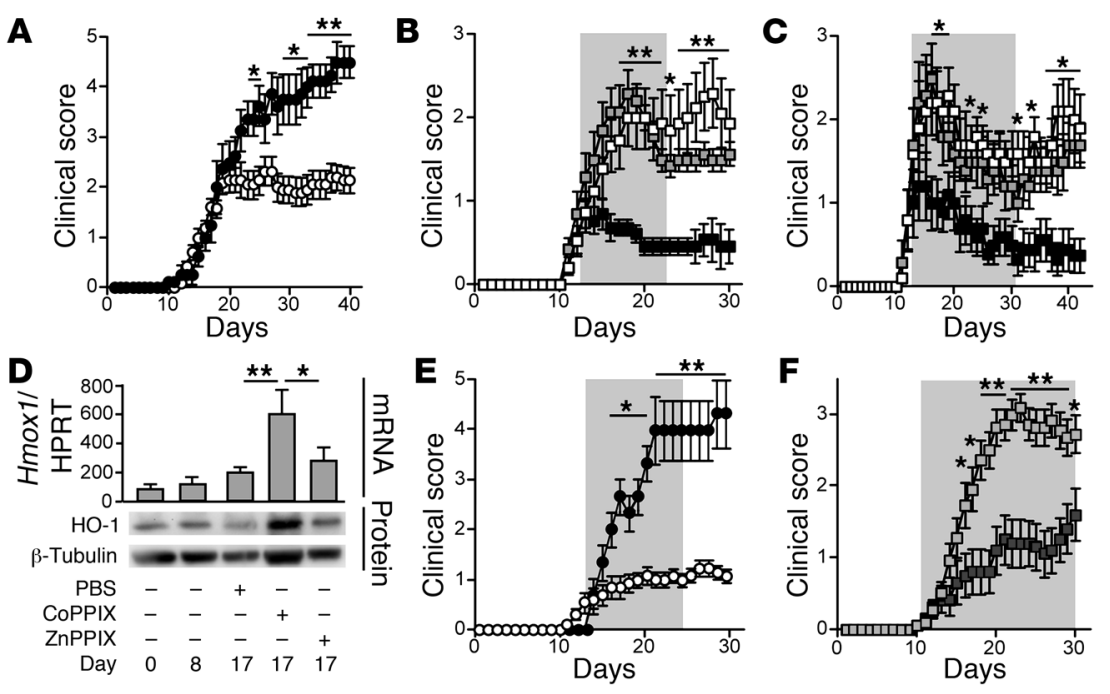

Figure 1

HO-1 and CO suppress EAE progression. EAE was induced, and disease severity was scored daily thereafter. Clinical scores are shown as mean \pm SEM. (A) Progression of EAE in C57BL/6 Hmox1+/+ (open circles; $n=21$ ) versus $\mathrm{Hmox} 1^{-/-}$(filled circles; $n=8$ ) mice. (B and $\mathbf{C})$ C57BL/6 (B) or SJL/J (C) mice, randomized 2 days after EAE onset, were treated daily with PBS (open squares; $n=10-15$ ), CoPPIX (filled squares; $n=10-14$ ), or ZnPPIX (gray squares; $n=10-14$ ). (D) C57BL/6 Hmox ${ }^{+/+}$mice were treated as in B. Hmox1 mRNA and protein expression in the CNS were assessed by quantitative RT-PCR and Western blotting, respectively. Hmox 1 mRNA expression is shown as mean number of Hmox1 per HPRT mRNA molecules \pm SD. (E) EAE was induced in C57BL/6 Hmox1 ${ }^{+/+}$(open circles; $n=12$ ) and $\mathrm{Hmox}^{-/-}$(filled circles; $n=3$ ) mice treated with CoPPIX as in $\mathbf{B}$. (F) EAE was induced in C57BL/6 Hmox1+/+ mice, randomized 10-12 days after immunization, and exposed to CO (450 ppm; dark gray squares; $n=20$ ) or not (light gray squares; $n=22$ ). Shaded areas indicate periods of designated treatment. ${ }^{\star} P<0.05$; ${ }^{\star \star} P<0.01$.

Induction of HO-1 expression and function by administration of cobalt protoporphyrin IX (CoPPIX) after EAE onset (i.e., disease incidence, $37 \%$; mean clinical score, $0.7 \pm 0.1$ ) reversed paralysis and led to complete disease remission in $66.6 \%$ of mice compared with controls treated with vehicle (PBS) or zinc protoporphyrin IX (ZnPPIX; Figure 1B and Table 2). To address whether similar effects would occur in other mouse strains, EAE was induced in $\mathrm{SJL} / \mathrm{J}$ mice by immunization with the proteolipid protein peptide 139-151 (PLP $139-151)$. Induction of HO-1 by administration of CoPPIX after EAE onset in SJL/J mice (disease incidence, $40 \%$; mean clinical score, $0.8 \pm 0.2$ ) reversed paralysis and led to complete disease remission in $75 \%$ of afflicted mice (Figure $1 \mathrm{C}$ and Table 2). Moreover, disease relapse was also suppressed in SJL/J mice treated with CoPPIX (Figure 1C and Table 2). That CoPPIX induced HO-1 expression in C57BL/6 mice with established EAE was confirmed at the mRNA and protein levels (Figure 1D). CoPPIX induced a 3 -fold increase in Hmox 1 mRNA expression in the CNS compared with PBS-treated controls $(P<0.01$; Figure 1D). Hmox 1 mRNA was not significantly induced upon ZnPPIX administration (Figure 1D). Expression of $\mathrm{HO}-1$ protein was confirmed using protein extracts from the CNS (Figure 1D).

When used at the same dose and schedule shown to arrest EAE progression in $H \operatorname{mox} 1^{+/+}$ C57BL/ 6 mice (Figure 1B), CoPPIX failed to arrest EAE progression in Hmox $1^{-/-} \mathrm{C} 57 \mathrm{BL} / 6$ mice (Fig-
Table 1

$\mathrm{HO}-1$ controls the pathogenesis of EAE

\begin{tabular}{|c|c|c|c|c|c|}
\hline Genotype & $n$ & $\begin{array}{c}\text { Incidence } \\
(\%)\end{array}$ & $\begin{array}{c}\text { Onset } \\
\text { (d; } \pm \text { SEM) }\end{array}$ & $\begin{array}{l}\text { Maximal clinical } \\
\text { score }( \pm \text { SEM) }\end{array}$ & $\begin{array}{c}\text { Mortality } \\
(\%)\end{array}$ \\
\hline Hmox1+/+ & 8 & 95 & $16 \pm 1.01$ & $2.3 \pm 0.35$ (day 26$)$ & 19.04 \\
\hline Hmox1-- & 21 & 100 & $15.5 \pm 0.73$ & $4.5 \pm 0.37(\text { day } 40)^{\mathrm{A}}$ & $75^{\mathrm{B}}$ \\
\hline
\end{tabular}

$\mathrm{AP}=0.0053$ versus $H \operatorname{mox} 1^{+/+} .{ }^{B} P=0.002$ versus $H \operatorname{mox} 1^{+/+}$. ure $1 \mathrm{E})$, confirming that the protective effect of CoPPIX requires the expression of $\mathrm{HO}-1$.

We have previously shown that exogenous $\mathrm{CO}$ can mimic the protective effects of $\mathrm{HO}-1$ in several inflammatory conditions (21) (reviewed in ref. 8). To determine whether this was the case in EAE, C57BL/ 6 mice were exposed to $\mathrm{CO}$ via inhalation (EAE incidence, $17 \%$; mean clinical score, $0.3 \pm 0.1$ ). CO arrested EAE progression and paralysis when compared with air inhaled under similar flow conditions (Figure $1 \mathrm{~F}$ and Table 2). We asked whether expression of HO-1 during the course of EAE prevented CNS demyelination, the main cause of paralysis associated with EAE (reviewed in refs. 2-4). CNS demyelination was more pronounced in Hmox $1^{-/-}$versus $H \operatorname{mox} 1^{+/+}$C57BL/6 mice as assessed 60 days after the induction of EAE (Supplemental Figure 1, A-F; supplemental material available online with this article; doi:10.1172/JCI28844DS1). Induction of HO-1 after EAE onset in SJL/J mice prevented CNS demyelination compared with ZnPPIX- or PBStreated controls (Figure 2, A-C), an effect consistent with reduction of paralysis (Figure 1, A-C). Taken together, these observations suggest that the ability of $\mathrm{HO}-1$ to revert paralysis during the progression of EAE is associated with inhibition of CNS demyelination.

HO-1 modulates the effector function of pathogenic Th cells. Inhibition of EAE progression and relapse in SJL mice treated with CoPPIX was associated with a $87.2 \% \pm 20 \%(P=0.0033)$ and $62.4 \% \pm 40 \%(P=0.013)$ reduction of inflammatory foci in the CNS parenchyma and meninges, respectively, compared with vehicle-treated controls (Figure 2, D-G). ZnPPIX, a protoporphyrin that inhibits $\mathrm{HO}$ enzymatic activity, increased by 2.3 -fold the total number of inflammatory foci (i.e., parenchyma and meninges) compared with vehicle-treated controls $(P=0.0003)$, suggesting again that endogenous HO-1 activity counters neuroinflammation associated with EAE progression (Figure 2, D-G). However, this effect was not reflected by an increase in the clinical scores of the disease (Figure 1C).

The ability of HO-1 induction to reduce the formation of inflammatory foci in the CNS (Figure 2G) was paralleled by a similar reduction in the total number of leukocytes detected within the CNS. Significant numbers of leukocytes (CD45 high) were detected in the CNS of C57BL/6 mice with EAE (Supplemental Figure 2). These were composed primarily of $\mathrm{CD}^{+} \mathrm{Th}$ cells, $\mathrm{CD}^{+} \mathrm{T}$ cells, 


\section{Table 2}

Induction of $\mathrm{HO}-1$ or $\mathrm{CO}$ exposure suppresses EAE

$\begin{array}{lccccc}\text { Strain } & \text { Treatment } & \boldsymbol{n} & \begin{array}{c}\text { Maximal clinical } \\ \text { score }( \pm \text { SEM) }\end{array} & \begin{array}{c}\text { Mortality } \\ \mathbf{( \% )}\end{array} & \begin{array}{c}\text { Remission } \\ \mathbf{( \% )}\end{array} \\ \text { C57BL/6 } & \text { PBS } & 15 & 2.33 \pm 0.44 \text { (day 28) } & 20 & 0 \\ \text { C57BL/6 } & \text { CoPPIX } & 14 & 0.84 \pm 0.21 \text { (day 15) } & 0 & 66.6^{\mathrm{B}} \\ \text { C57BL/6 } & \text { ZnPPIX } & 14 & 2.28 \pm 0.22(\text { day 18) } & 20^{\circ} & 0 \\ \text { SJL/J } & \text { PBS } & 10 & 2.3 \pm 0.36 \text { (day 20) } & 0 & 11.1 \\ \text { SJL/J } & \text { CoPPIX } & 10 & 1.2 \pm 0.45 \text { (day 16) } & 0 & 75.0^{\mathrm{E}} \\ \text { SJL/J } & \text { ZnPPIX } & 10 & 2.5 \pm 0.44 \text { (day 17) } & 0 & 11.1 \\ \text { C57BL/6 } & \text { Air } & 10 & 3.09 \pm 0.26(\text { day 23) } & 22.7 & 0 \\ \text { C57BL/6 } & \text { CO } & 10 & 1.9 \pm 0.69 \text { (day 30) } & 15^{\mathrm{C}} & 0\end{array}$

${ }^{A} P=0.0117$ versus PBS-treated C57BL/6. ${ }^{B} P<0.05$ versus PBS- and ZnPPIX-treated C57BL/6. ${ }^{C} P=$ NS. ${ }^{D} P=0.0278$ versus PBS-treated SJL/J. $E P<0.05$ versus PBS- and ZnPPIX-treated SJL/J. $F P=0.009$ versus air-treated C57BL/6.

TNF- $\alpha$ expression in these cells compared with PBS-treated controls (Figure 3B and Supplemental Figure 3B). The frequency of Th cells expressing IL-10 (Figure 3B) was not modulated by HO-1, an effect that should contribute to suppressing EAE progression as well.

We asked whether the protective effect of HO-1 was associated with modulation of regulatory $\mathrm{T}$ cells within the CNS. The frequency of forkhead box $\mathrm{p} 3$-positive $\left(\mathrm{Foxp}^{+}\right)$regulatory $\mathrm{T}$ cells within the CNS was not modulated by HO-1 induction (Figure 3B and Supplemental Figure 3C), suggesting that the protective effect of HO-1 may act independently of regulatory $\mathrm{T}$ cells.

We tested whether expression of Th cell activation surface markers, including CD69, CD25, CD44, and CD62 ligand (CD62L), were modulated by HO-1 induction. We found that this was

and $\mathrm{CD} 45^{\text {high }} \mathrm{CD} 11 \mathrm{~b}^{+}$macrophages $(\mathrm{M} \phi$; Figure $3 \mathrm{~A}$ and Supplemental Figure 2). Induction of HO-1 by CoPPIX decreased by $80 \% \pm 6 \%$ the total number of leukocytes within the CNS compared with PBS-treated controls $(P<0.001$; Figure 3A). This decrease was reflected by an $83 \% \pm 7 \%$ decrease in Th cells $(P<0.001)$ and a $67 \% \pm 17 \%$ decrease in $\mathrm{CD}^{+} \mathrm{T}$ cells $(P<0.001)$ compared with PBS-treated controls (Figure 3A). These data demonstrate that $\mathrm{HO}-1$ induction after EAE onset significantly decreases the number of CNS leukocytes and the formation of inflammatory foci within the CNS.

We tested whether HO-1 interfered with the activation, proliferation, and/or acquisition of effector function by CNSinfiltrating Th cells. Induction of HO-1 by CoPPIX reduced by $57 \% \pm 2 \%$ the frequency of Th cells undergoing cell cycle progression $\left(\mathrm{BrdU}^{+} ; P=0.028\right)$ and by $51.5 \% \pm 34 \%$ that of $\mathrm{Th}$ cells expressing IL-2 $(P<0.01)$ compared with vehicle-treated controls (Figure 3B and Supplemental Figure 3A). This suggests that induction of $\mathrm{HO}-1$ suppresses Th cell proliferation within the CNS, an effect that should contribute to suppressing EAE progression.

The pathogenic function of CNS-infiltrating Th cells was also modulated by upregulation of HO-1 in that HO-1 targeted specifically the expression of IFN- $\gamma$ in Th cells. Control-treated mice with EAE had $24 \% \pm 4 \%$ CNS-infiltrating Th cells expressing intracellular TNF- $\alpha$ and IFN- $\gamma$ (Supplemental Figure 3B). Induction of HO- 1 by CoPPIX reduced by $60 \% \pm 3 \%$ the frequency of Th cells expressing IFN- $\gamma$ but failed to affect

\section{Figure 2}

Induction of HO-1 prevents CNS demyelination and formation of inflammatory foci. SJL/mice, randomized 2 days after EAE onset, were treated daily with PBS (A and D), CoPPIX (B and E), or ZnPPIX (C and F). Representative Luxol fast blue (A-C) and hematoxylin and eosin (D-F) spinal cords staining with adjacent peripheral nerve root are shown 40 days after disease induction. Original magnification, $\times 160$. Note the presence of some edema of myelin (A) and meningeal inflammation (D) in PBS-treated controls, intact myelin (B) and mild meningeal inflammation (E) in CoPPIX-treated mice, and demyelination $(\mathbf{C})$ and marked meningeal and parenchymal inflammation (F) in ZnPPIX-treated mice. (G) The number of inflammatory foci in the meninges and parenchyma as well as the total (meninges plus parenchyma) were quantified and are shown as mean $\pm \mathrm{SD}$ ( $n=8-10$ per group). ${ }^{* *} P<0.01$.

not the case for the frequency of Th cells expressing these markers (Supplemental Figure 4) or for their relative level of expression (data not shown).

The frequency of CNS-infiltrating $\mathrm{CD}^{+} \mathrm{T}$ cells undergoing cell cycle progression $\left(\mathrm{BrdU}^{+}\right)$was reduced by $55 \% \pm 21 \%$ when $\mathrm{HO}-1$ was induced compared with vehicle-treated controls $(P=0.028$; Figure 3C and Supplemental Figure 3D), an effect that should contribute to suppressing EAE progression (2-4). Induction of HO-1 did not modulate IFN- $\gamma$ or TNF- $\alpha$ expression by CNS-infiltrating CD8+ T cells (Figure 3C).

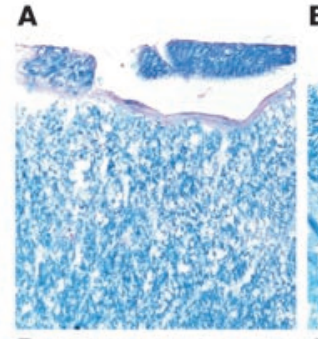

D

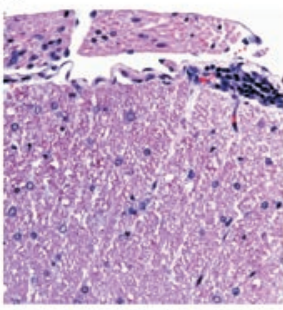

G

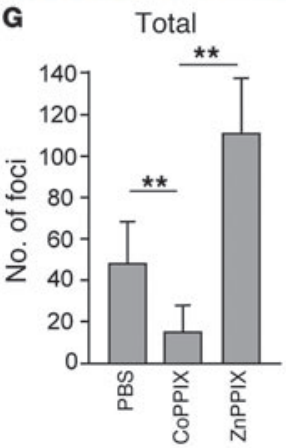

B

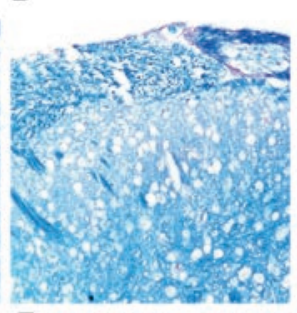

E
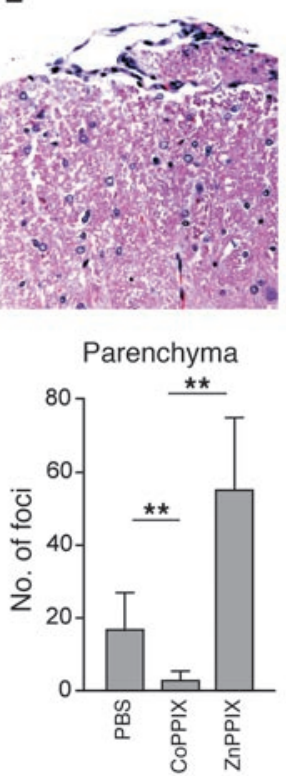

C

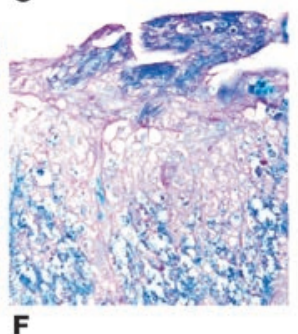

F
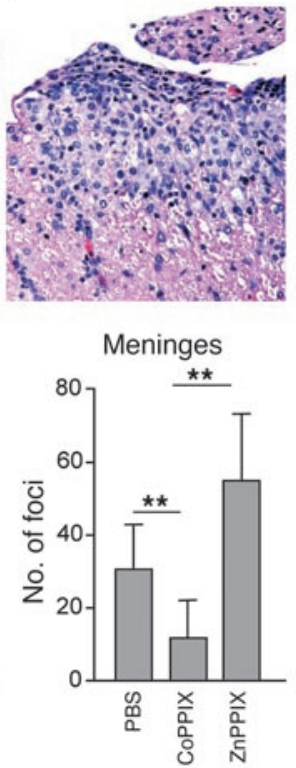

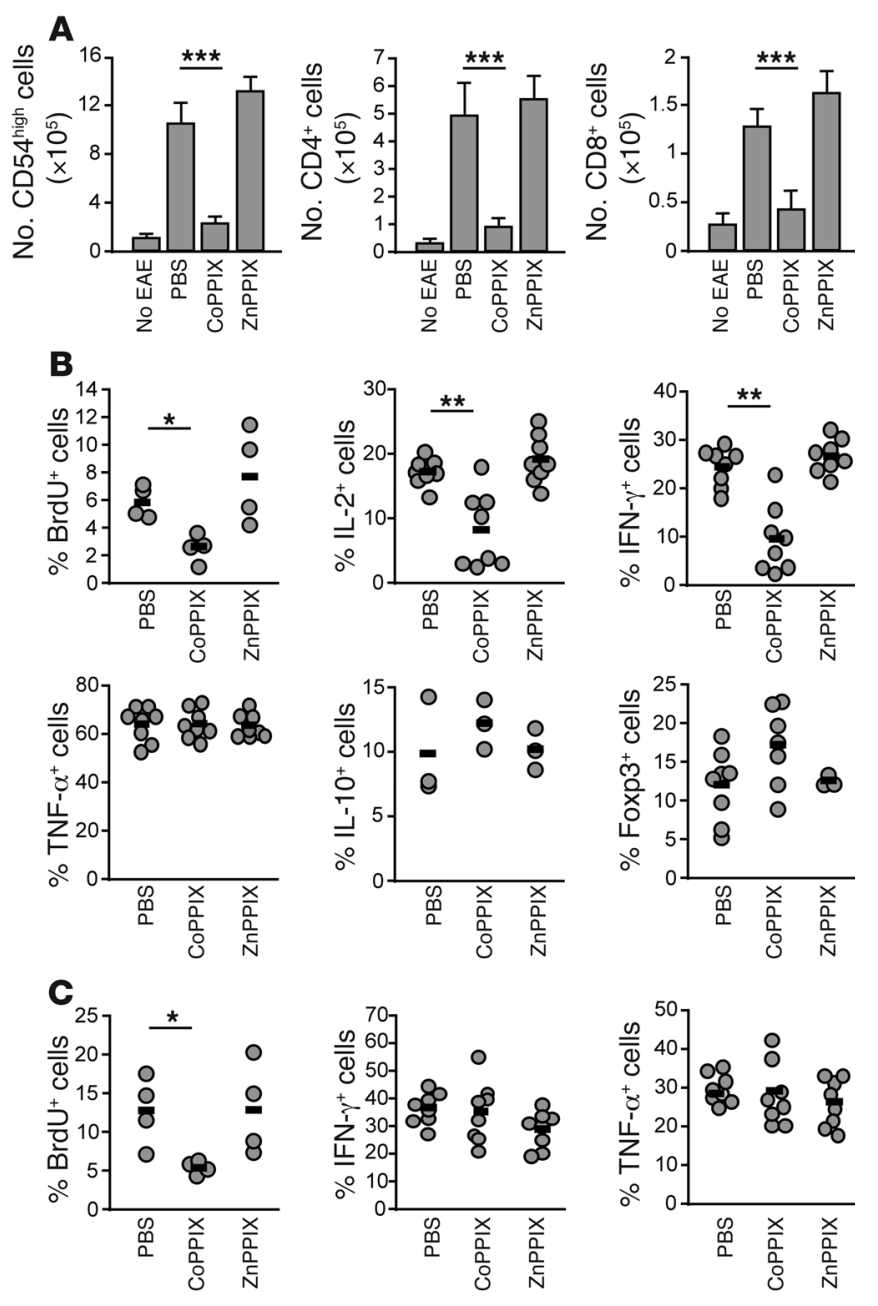

HO-1 and CO suppress myelin-reactive Th cell reactivation. We hypothesized that HO-1 induction might interfere with the reactivation of primed myelin-reactive Th cells that occurs in the CNS during the development of EAE and presumably also occurs in MS patients. Induction of HO- 1 by CoPPIX reduced myelin-reactive Th cell proliferation by $60.5 \% \pm 3 \%$ compared with vehicle- or ZnPPIX-treated controls $(P<0.001$; Figure 4A). Moreover, HO-1 induction did not affect the proliferative response of draining lymph node Th cells to concanavalin A (ConA; Supplemental Figure 5A) nor did it reduce Th cell numbers in draining lymph nodes (data not shown).

In the same experimental system, induction of HO- 1 suppressed secretion of TNF- $\alpha$ by $64 \% \pm 2 \%(P<0.001)$, IFN- $\gamma$ by $75 \% \pm 2 \%$ $(P<0.001)$, and IL-12/23(p40) by $61 \% \pm 16 \%(P<0.01)$ compared with controls (Figure 4B). This suggests that HO-1 suppresses the differentiation of primed myelin-reactive Th cells toward a pathogenic effector phenotype characterized by the secretion of proinflammatory cytokines.

To assess whether suppression of Th cell reactivation in vitro was due to defective priming of naive myelin-reactive Th cells in vivo, draining lymph node Th cells $\left(>98 \% \mathrm{CD}^{+}\right)$were isolated 7 days after immunization and rechallenged in vitro with $\mathrm{MOG}_{35-55}$ in the presence of naive APCs $\left(<2 \% \mathrm{CD} 4^{+}\right)$. Proliferation of myelin-reactive Th cells from CoPPIX-treated mice was similar to that of control mice (Supplemental Figure 5A), suggesting that

\section{Figure 3}

Induction of $\mathrm{HO}-1$ reduces the number of $\mathrm{Th}$ and $\mathrm{CD} 8^{+} \mathrm{T}$ cells within the CNS and suppresses Th cell effector function. C57BL/6 mice, randomized 2 days after EAE onset, were treated daily with PBS, CoPPIX, or ZnPPIX. Leukocyte CNS infiltrates were analyzed by flow cytometry 20 days after immunization. (A) Number of CD45 high (leukocytes), CD4+ Th, and CD8 ${ }^{+} \mathrm{T}$ cells are shown as mean $\pm \mathrm{SD}(n=4-5$ per group). (B) Percentages of CNS CD4+ Th cells expressing intracellular BrdU (S phase cell cycle progression), IL-2, IFN- $\gamma$, TNF- $\alpha$, IL-10, and Foxp3 (regulatory T cells). (C) Percentage of CNS CD8 ${ }^{+}$T cells expressing intracellular BrdU, IFN- $\gamma$, and TNF- $\alpha$. Each value in $\mathbf{B}$ and $\mathbf{C}$ represents an individual animal. Bars indicate mean values of all mice analyzed in each group. ${ }^{\star} P<0.05$; ${ }^{* *} P<0.01 ;{ }^{* \star} P<0.001$.

HO-1 induction did not interfere with priming of naive myelinreactive Th cells in vivo.

Exposure of C57BL/ 6 mice to CO inhibited by $71 \% \pm 5 \%$ the proliferative response of myelin-reactive Th cells compared with control mice exposed to air under similar flow conditions $(P=0.0016$; Figure 4C). In the same experimental setting, CO inhibited TNF- $\alpha$ secretion by $40 \% \pm 2 \%(P=0.0029)$ but failed to inhibit IFN- $\gamma$ secretion (Figure 4D). This suggests that the immunomodulatory effect of $\mathrm{CO}$ may be more restricted than that of $\mathrm{HO}-1$ induction.

HO-1 expression in APCs inhibits myelin-reactive Th cell proliferation. We reasoned that inhibition of Th cell proliferation could result from induction of HO-1 expression in Th cells $(22,23)$ and/or in APCs (24). To test the first possibility, Th cells were purified from $\mathrm{MOG}_{35-55}$-immunized mice in which $\mathrm{HO}-1$ was induced. Proliferation of Th cells from CoPPIX-treated mice was not significantly inhibited in the presence of APCs isolated from immunized but otherwise untreated mice compared with PBS- or ZnPPIX-treated controls (Figure 4E). This suggests that HO-1 expression in Th cells is not sufficient per se to suppress Th cell proliferation.

That the antiproliferative effect of HO- 1 is exerted via APCs is suggested by the following set of observations. Proliferation of purified myelin-reactive Th cells from immunized but otherwise untreated mice was inhibited by $65 \% \pm 7 \%$ in the presence of purified APCs from immunized mice treated with CoPPIX compared with control APCs isolated from PBS- or ZnPPIX-treated immunized controls $(P<0.001$; Figure 4F). Th cell proliferation was inhibited by $59 \% \pm 3 \%$ $(P<0.01)$ by DCs $\left(>98 \%\right.$ CD11c ${ }^{+}$; Figure $\left.4 \mathrm{G}\right)$ but not by B cells (>98\% CD19+; Figure 4H) isolated from CoPPIX treated immunized mice compared with DCs or B cells isolated from control PBS- or ZnPPIX-treated immunized mice, respectively.

Administration of CoPPIX to C57BL/6 mice after EAE onset induced high levels of HO-1 expression in CNS-infiltrating DCs $\left(\mathrm{CD} 11 \mathrm{c}^{+}\right)$compared with PBS- or ZnPPIX-treated controls (Figure 5A). Similar effects were observed in vitro: CoPPIX induced a 64-fold increase in Hmox 1 mRNA expression in bone marrow-derived DCs (approximately 80\% CD $11 c^{+}$) compared with vehicle-treated controls (Figure 5B). While Hmox 1 mRNA expression was also induced by ZnPPIX, this effect was significantly less pronounced than that of CoPPIX (Figure 5B). These observations are consistent with the notion that ZnPPIX can induce HO-1 expression moderately while inhibiting its activity strongly, thus acting as a potent HO-1 inhibitor (25). In the same experimental setting, CoPPIX induced HO-1 protein expression while ZnPPIX failed to do so (Figure 5B). To ensure that CoPPIX induced HO-1 expression specifically in DCs and not in a putative contaminating cell population, bone marrow-derived DCs were further purified 

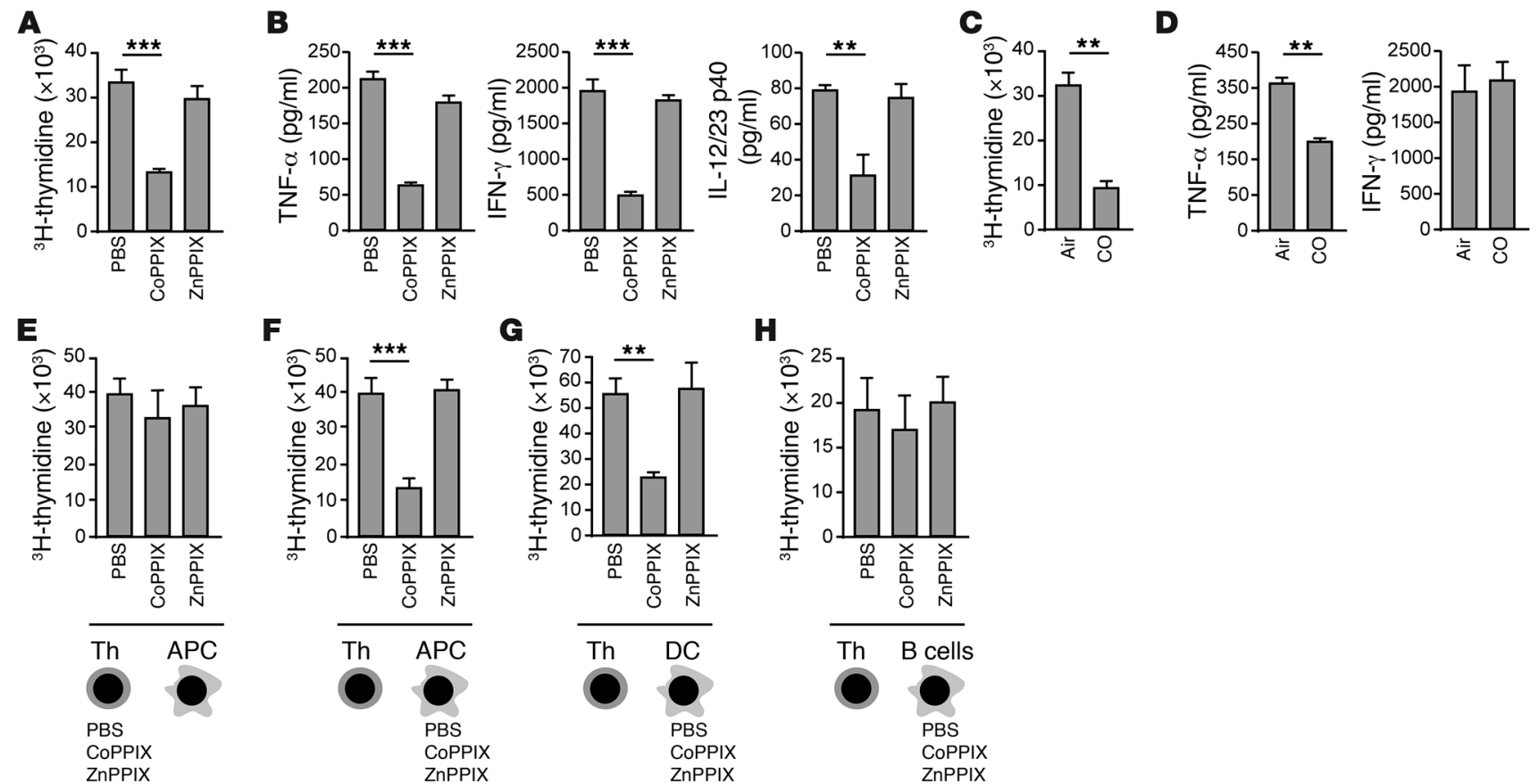

\section{Figure 4}

The antiproliferative effect of HO-1 is exerted via APCs. Results shown are mean \pm SD from triplicate samples in 1 of at least 3 independent assays, except for IL-12/23(p40) (1 assay). (A) C57BL/6 mice were treated as described in Methods. Eight days after immunization, proliferation of myelin-reactive Th cells was assessed in vitro 72 hours after addition of $\mathrm{MOG}_{35-55}(10 \mu \mathrm{g} / \mathrm{ml})$. (B) Cytokines were assayed in the cell culture supernatants $\left(100 \mu \mathrm{g} / \mathrm{ml} \mathrm{MOG}_{35-55}\right.$ for 72 hours). (C) C57BL/6 mice were exposed to air $(n=3)$ or CO $(450$ ppm; $n=3)$ starting 2 days prior to immunization. Th cell proliferation was assayed as in A. (D) Mice were treated as in C, and cytokines were assayed as in B. (E-H) C57BL/6 mice were treated as in A. (E) Th cells $\left(>98 \%\right.$ CD4 $\left.4^{+}\right)$from PBS-, CoPPIX-, or ZnPPIX-treated mice $(n=5)$ were cocultured with APCs $(<98 \%$ $\mathrm{CD}^{+}$) from immunized but otherwise untreated mice. Th cell proliferation was measured as in $\mathbf{A}$. Th cells from untreated immunized mice were cocultured with (F) APCs (<2\% CD4+), (G) DCs (>98\% CD11 c $^{+}$), or $(\mathbf{H})$ B cells $(>98 \%$ B220+) from PBS-, CoPPIX-, or ZnPPIX-treated immunized mice $(n=5)$. Th cell proliferation was measured as in $\mathbf{A} .{ }^{* \star} P<0.01 ;{ }^{* \star} P<0.001$.

(>98\% CD $\left.11 \mathrm{c}^{+}\right)$. That CoPPIX induced HO-1 expression specifically in CD11 $\mathrm{c}^{+}$cells was shown by immunocytochemistry (Figure 5C) and Western blot (Figure 5D). These data demonstrate that CoPPIX, but not ZnPPIX, induces HO-1 expression in DCs, a finding concordant with those of others (24).

HO-1 suppresses MHC class II expression in activated APCs. To evaluate further the impact of HO-1 in APC function, draining lymph node DCs from immunized C57BL/ 6 mice were analyzed by flow cytometry. Induction of $\mathrm{HO}-1$ by CoPPIX reduced by $39 \% \pm 12 \%$ MHC class II expression in DCs $\left(\mathrm{CD} 11 \mathrm{c}^{+}\right)$compared with controls $(P<0.001$; Figure 6A). This effect was specific to MHC class II, as expression of CD40, CD80, and CD86 were not significantly affected (Supplemental Figure 6A). Induction of HO-1 did not alter the frequency or total number of DCs in the draining lymph nodes of immunized mice (data not shown). Exogenous CO inhibited by $24 \% \pm 8 \%$ MHC class II expression in DCs compared with air-treated controls $(P=0.0011$; Figure 6B). This effect was again specific to MHC class II, as CO failed to inhibit the expression of CD40, CD80, or CD86 (Supplemental Figure 6B).

To test whether HO-1 and/or CO would affect other APC populations involved in the pathogenesis of $\operatorname{EAE}(26,27)$, MHC class II expression was analyzed in microglia $\left(\mathrm{CD} 45^{\text {low }} \mathrm{CD} 11 \mathrm{~b}^{+}\right)$and CNS-infiltrating $\mathrm{M} \phi\left(\mathrm{CD} 45^{\text {high }} \mathrm{CD} 11 \mathrm{~b}^{+}\right)$of $\mathrm{C} 57 \mathrm{BL} / 6$ mice with established EAE. Induction of HO-1 starting 2 days after disease onset (approximately 40\% EAE incidence) reduced MHC class II expression by $44 \% \pm 13 \%$ in microglia $(P<0.05$; Figure $6 \mathrm{C})$ and by $47 \% \pm 24 \%$ in CNS-infiltrating $\mathrm{M} \phi(P<0.05$; Figure $6 \mathrm{D})$ compared with controls.

MHC class II-expressing cells in the CNS of mice with established EAE was confined to the perivascular area and associated primarily with CNS-infiltrating leukocytes, i.e., M $\phi$ (Figure 6, E and F). Lowlevel MHC class II expression was also detected in the parenchyma, presumably associated with microglia (data not shown). Induction of HO-1 by CoPPIX reduced MHC class II expression in both perivascular leukocytes and microglia (Figure 6, E and F), confirming similar observations made by flow cytometry

To address further the mechanism by which HO-1 suppressed MHC class II expression in CNS APCs, we tested whether induction of HO-1 in microglial BV2 cells would inhibit MHC class II expression. When stimulated in vitro with IFN- $\gamma$, microglial BV2 cells upregulated the expression of MHC class II (Figure 7, A and B). Induction of $\mathrm{HO}-1$ by CoPPIX inhibited by $27 \% \pm 7 \% \mathrm{MHC}$ class II expression compared with controls ( $P<0.05$; Figure 7A). Exposure to $\mathrm{CO}$ mimicked this effect, inhibiting by $20 \% \pm 7 \%$ MHC class II expression compared with air-treated controls $(P<0.05$; Figure $7 \mathrm{~B})$. Induction of $\mathrm{HO}-1$ or exposure to $\mathrm{CO}$ had no effect on $\mathrm{CD} 40$, CD80, or CD86 expression in BV2 cells (data not shown). Induction of HO-1 inhibited IFN- $\gamma$-driven phosphorylation of STAT-1 without affecting STAT-1 expression (Figure 7C). Induction of MHC class II transcription activator (CIITA) mRNA expression by IFN- $\gamma$ was inhibited by $30 \% \pm 11 \%$ compared with controls $(P<0.05$; Figure 7D). Given the central role of STAT-1 phosphorylation and CIITA 

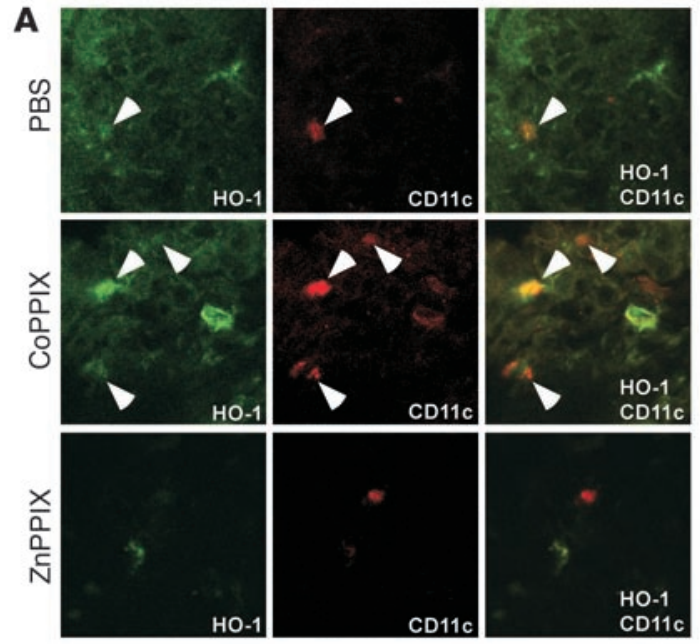

$\mathbf{B}$
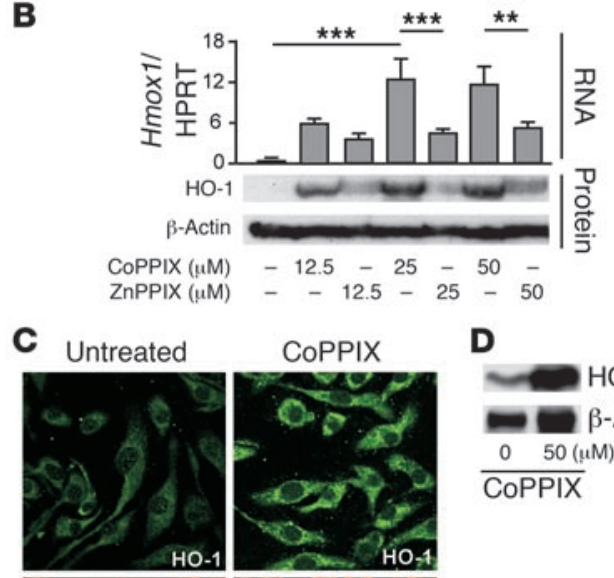

\section{D}
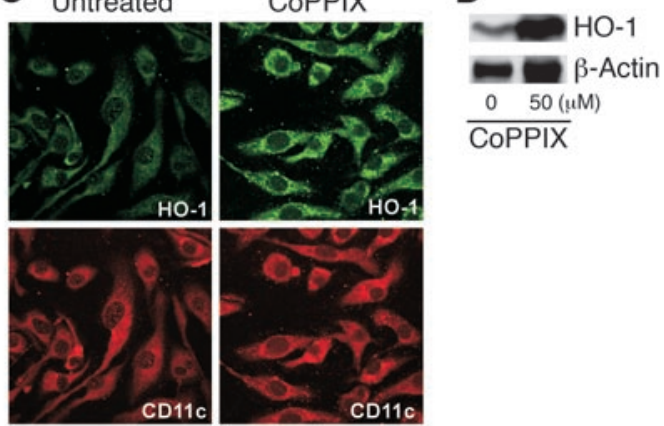

\section{Figure 5}

CoPPIX induces HO-1 expression in DCs in vivo and in vitro. (A) C57BL/6 mice were randomized 2 days after EAE onset and treated daily with PBS, CoPPIX, or ZnPPIX. HO-1 and CD11c (DC) expression in spinal cords was detected by immunocytochemistry 7 days after beginning treatments and analyzed by confocal microscopy. Shown are $\mathrm{HO}-1$ (left panels), CD11c (middle panels) and CD11c plus HO-1 (right panels). Original magnification, $\times 240$. Arrows indicate positive staining. (B) Unsorted bone marrow-derived DCs (approximately $80 \%$ CD11 $\mathrm{c}^{+}$) were exposed to CoPPIX or ZnPPIX, and Hmox1 mRNA and protein expression were assessed by quantitative RT-PCR and Western blotting, respectively. Hmox1 mRNA is shown as mean number of Hmox1 per HPRT mRNA molecules \pm SD ( $n=3$ per group). (C) Bone marrow-derived DCs were purified $\left(>98 \% \mathrm{CD} 11 \mathrm{C}^{+}\right)$and exposed to CoPPIX (50 $\mu \mathrm{M}$ for 16 hours) as in B. HO-1 (green) and CD11c (red) were detected as in A. Original magnification, $\times 400$. (D) Expression of $\mathrm{HO}-1$ was detected by Western blot in purified DCs shown in $\mathbf{C}$. ${ }^{\star \star} P<0.01 ;{ }^{* \star} P<0.001$.

$\mathrm{CO}$ contributes to the protective effects of $\mathrm{HO}-1$, as exposure of $\mathrm{Hmox}^{+/+}$mice to $\mathrm{CO}$ mimicked the protective effects of $\mathrm{HO}-1$ (Figure 1F, Figure 4, C and D, Figure 6B, and Figure 7B). One would expect, however, that other end products of heme degradation, e.g., biliverdin, may act in a similar manner (30). However, biliverdin does not suppress myelin-reactive Th cell proliferation, nor does it suppress EAE progression (Supplemental Figure 7). One possible explanation may be that the protective effect of $\mathrm{HO}-1$ is exerted within the CNS, which biliverdin cannot enter because of its exclusion by the blood-brain barrier.

Our data suggest that the mechanism underlying the protective effect of HO-1 is associated with a profound inhibition of leukocyte accumulation (Figure $2 \mathrm{G}$ and Figure $3 \mathrm{~A}$ ) and reactivation (Figure 3, B and C) within the CNS. This is suggested by the observation that $\mathrm{HO}-1$ induction by CoPPIX administration after EAE onset reduced the number of inflammatory foci (Figure $2 \mathrm{G}$ ) as well as the total number of CNS Th cells, $\mathrm{CD}^{+} \mathrm{T}$ cells, and $\mathrm{M} \phi$ (Figure $3 \mathrm{~A})$ and in addition suppressed the proliferation of the remaining Th and $\mathrm{CD}^{+} \mathrm{T}$ cells (Figure $3, \mathrm{~B}$ and $\mathrm{C}$ ) infiltrating the CNS.

The antiproliferative effect of $\mathrm{HO}-1$ was shown in vitro to be strictly dependent on DCs (Figure 4G) that express high levels of HO-1 (Figure 5, B and C). That a similar effect may occur in vivo to arrest EAE progression is suggested by the observation that DCs expressing high levels of HO-1 were detected in the CNS of CoPPIX-treated mice in which EAE progression was arrested (Figure 5A).

Induction of $\mathrm{HO}-1$ leads to specific inhibition of MHC class II in APCs, including DCs (Figure 6, A and B), microglia (Figure 6C), and CNS-infiltrating $\mathrm{M} \phi$ (Figure 6D). Induction of HO-1 expression in microglia suppressed STAT-1 phosphorylation as well as CIITA expression, 2 critical events for MHC class II expression in APCs (28) (reviewed in ref. 29) as well as in the reactivation of myelin-reactive Th cells in the CNS (31). This effect is likely to contribute to the overall protective effect of $\mathrm{HO}-1$ induction, as MHC class II expression in microglia is thought to be involved in EAE pathogenesis and progression (reviewed in refs. 32, 33).

That inhibition of MHC class II accounts for the protective effect of HO-1 is supported by the association between certain human MHC class II locus alleles and MS susceptibility (reviewed in ref. 34). Moreover, peptides that interfere directly with MHC class II-mediated antigen presentation to myelin-reactive Th cells are very efficient in arresting EAE progression (35) (reviewed in ref. 2), suggesting again that inhibition of MHC class II expression 
A

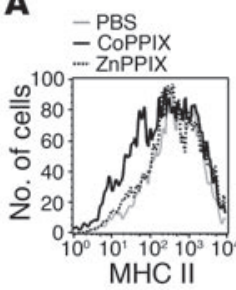

B

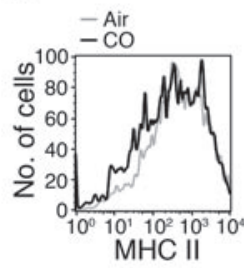

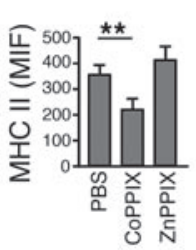

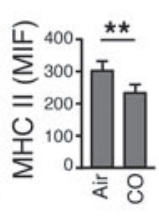

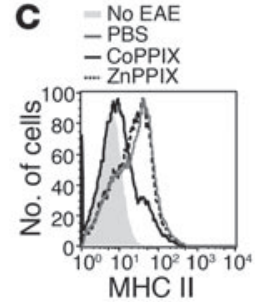
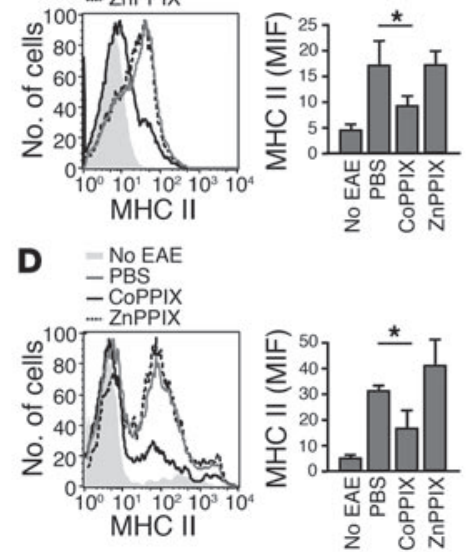

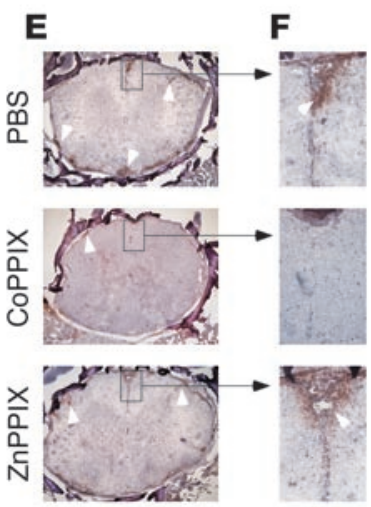

\section{Figure 6}

Induction of HO-1 and exposure to CO inhibit MHC class II expression in APCs. (A) C57BL/6 mice were treated daily with PBS, CoPPIX, or ZnPPIX $(n=4-6)$ starting 2 days prior to footpad immunization. Draining lymph node cells were isolated, and surface MHC class II expression was analyzed in DCs $\left(\mathrm{CD} 11 \mathrm{c}^{+}\right)$by flow cytometry 8 days after immunization. Representative histograms and quantifications (mean intensity of fluorescence; MIF) are shown as mean \pm SD. (B) C57BL/6 mice were exposed to air $(n=6)$ or CO $(450$ ppm; $n=7)$ starting 2 days prior to immunization and continuously thereafter. Draining lymph node cells were isolated, and surface MHC class II expression was assessed in DCs $\left(\mathrm{CD} 11 \mathrm{C}^{+}\right)$as in $\mathbf{A}$. Representative histograms and quantification are shown as mean \pm SD. (C and D) C57BL/6 mice, randomized 2 days after EAE onset, were treated daily with PBS, CoPPIX, or ZnPPIX ( $n=9$ per group). MHC class II expression in (C) microglia (CD45 lowCD11b+) and (D) CNS-infiltrating $\mathrm{M} \phi\left(C D 45^{\text {high }} \mathrm{CD} 11 \mathrm{~b}^{+}\right)$was analyzed by flow cytometry 20 days after immunization, when controls, i.e., ZnPPIX and PBS, reached maximal disease severity. Representative histograms and quantifications are shown as mean $\pm \mathrm{SD}$. (E and $\mathbf{F})$ EAE induction and treatments were performed as in $\mathbf{C}$ and $\mathbf{D}$. MHC class II expression was detected by immunocytochemistry and counterstained. Original magnification, $\times 10$ (E); $\times 40$ (F). White arrows indicate MHC class II expression. ${ }^{*} P<0.05 ;{ }^{* *} P<0.01$.

by APCs is probably sufficient to explain the protective effects of HO-1 observed herein. Another possibility would be that HO-1 promotes the accumulation of regulatory $\mathrm{T}$ cells and/or their activity within the CNS. This would be consistent with widespread evidence that regulatory $\mathrm{T}$ cells can control the pathogenesis of EAE $(6,36-38)$ as well as with the hypothesis that HO-1 expression may control regulatory $\mathrm{T}$ cell function (39). However, we observed that despite its ability to suppress ongoing EAE, induction of HO-1 failed to modulate the number of CNS-infiltrating regulatory $\mathrm{T}$ cells (Figure 3B). Furthermore, we also found that the number and function of regulatory $\mathrm{T}$ cells was unaffected in naive $H$ mox $1^{-/-}$

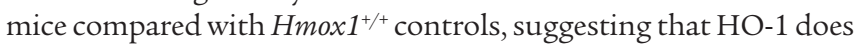
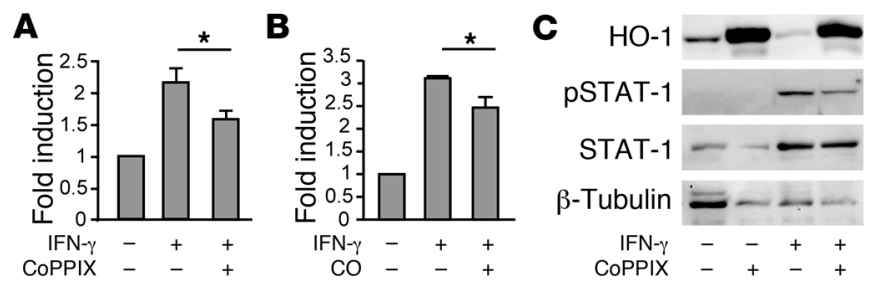

Figure 7

HO-1 inhibits STAT-1 phosphorylation and CIITA expression in CNS APCs. (A and B) Expression of MHC class II in microglial BV2 cells was monitored by flow cytometry. When indicated (+), BV2 cells were exposed to CoPPIX $(50 \mu \mathrm{M})$ or CO $(250 \mathrm{ppm}) 6$ or 16 hours, respectively, before IFN- $\gamma$ stimulation ( $50 \mathrm{U} / \mathrm{ml}$ for 24 hours). MHC class II expression is shown as fold induction versus untreated cells \pm SD $(n=3-7)$. (C) Phosphorylated STAT-1, total STAT-1, HO-1, and $\beta$-tubulin were detected by Western blot in BV2 cells treated as in A. (D) Expression of CIITA mRNA was quantified by real-time PCR in BV2 cells treated as in A. Results are shown as mean fold induction versus untreated cells $\pm \operatorname{SD}(n=3)$. ${ }^{*} P<0.05$.

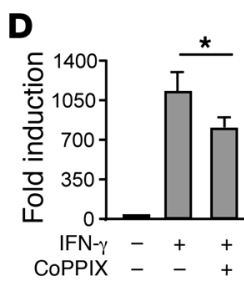

not influence regulatory $\mathrm{T}$ cell development and/or function (40). Taken together, these data suggest that the protective effect of HO-1 in EAE does not act via modulation of regulatory $\mathrm{T}$ cells.

That HO-1 exerts its protective effects via APCs, including CNS microglia (Figure 6, C and D), is relevant for its mechanism of action if one considers that immunomodulation within the CNS is probably required to arrest MS progression. This may explain the relative lack of efficiency in treating MS by controlling exclusively peripheral antigen presentation, which is probably not as relevant, whereas prevention of effector Th cell reactivation by CNS APCs almost certainly is $(26,31)$. Our finding that induction of HO-1 after EAE onset suppressed Th cell reactivation and effector function within the CNS (Figure 4B) may explain why this approach was effective in suppressing disease progression (Figure 1, $\mathrm{B}$ and $\mathrm{C}$, and Table 2).

Our present data suggest that upon induction of HO-1 in APCs, the effector function of myelin-reactive Th cells in the CNS is modulated in a manner that suppresses their pathogenicity. This is supported by the suppression of neuroinflammatory, i.e., IFN- $\gamma$, but not neuroprotective, i.e., IL-10 (41) and TNF- $\alpha$ (42), cytokine expression by CNS-infiltrating Th cells (Figure 3B). Presumably, inhibition of high-level IFN- $\gamma$ expression by CNS-infiltrating Th cells should promote oligodendrogenesis and thus aid to EAE remission (43). It should be noted, however, that while inhi- 
bition of IFN- $\gamma$ expression in CNS-infiltrating Th cells is likely to contribute to EAE regression (44), this remains to be formally established as EAE is exacerbated in IFN- $\gamma$-deficient mice (45).

One possibility not excluded by the present study is that HO-1 may prevent EAE progression not only by immunomodulation but also by its cytoprotective properties $(46,47)$ in the CNS, i.e., oligodendrocytes or neurons (48). Such an effect would be consistent with the observed arrest of EAE progression (49) as well as with our previous observation that cytoprotection afforded by HO-1 can prevent the rejection of transplanted organs (50).

Even with the caution necessary for extrapolating from EAE to MS, there are several independent lines of evidence suggesting that HO- 1 expression affects the clinical outcome of MS. First, HO-1 is expressed in the CNS of MS patients (9). Second, HO-1 prevents the deleterious effects of inflammation in humans (51). Third, a $(\mathrm{GT})_{\mathrm{n}}$ microsatellite polymorphism in the human $H M O X 1$ promoter controls HO-1 inducibility and dictates the incidence of several inflammatory diseases (reviewed in ref. 52). Additional studies are needed to determine whether HO-1 functions to prevent MS progression or promote its remission.

In conclusion, we found that HO- 1 suppresses the pathologic outcome of autoimmune neuroinflammation associated with the development of EAE. This effect is mediated at least in part by $\mathrm{CO}$, which acts on APCs to inhibit the expression of MHC class II and presumably the reactivation of pathogenic Th cells within the CNS. We suggest that modulation of HO-1 expression or administration of CO may be a useful therapeutic strategy to treat MS patients.

\section{Methods}

Animals. C57BL/6 and SJL/J mice were maintained under specific pathogen-free conditions approved by the Animal User and Institutional Ethical Comities of the Instituto Gulbenkian de Ciência and the Beckman Center for Molecular Medicine. Mice were used between 6 and 8 weeks of age. Hmox $1^{+/-}$mice were originally generated by S.-F. Yet (Brigham and Women's Hospital, Boston, Massachusetts, USA; ref. 53). Littermate Hmox1 $1^{+-}$ and $H$ mox $1^{+/+}$mice were used as controls.

Cells and reagents. Microglial BV2 cells, obtained from E. Blasi (University of Modena and Reggio Emilia, Modena, Italy), were cultured essentially as described previously (54). Recombinant mouse IFN- $\gamma$ (PeproTech) was used to induce MHC class II expression in BV2 cells. $\mathrm{MOG}_{35-55}$ was synthesized at the Biopolymers Laboratory of Harvard Medical School. PLP 139-151 was synthesized at the PAN Facility of the Beckman Center for Molecular and Cellular Medicine. CoPPIX, ZnPPIX (Frontier Scientific Inc.), and biliverdin hydrochloride (MP Biomedicals) were dissolved in $0.2 \mathrm{~N} \mathrm{NaOH}$, neutralized with $0.2 \mathrm{~N} \mathrm{HCl}$, adjusted to $1 \mathrm{mg} / \mathrm{ml}$ (CoPPIX and ZnPPIX) and $10 \mathrm{mM}$ (biliverdin) with distilled water, and sterilized by filtration.

Cytokine assays. Cell culture supernatants were used to measure TNF- $\alpha$, IFN- $\gamma$, and IL-12/23(p40) concentrations by ELISA according to the manufacturer's indications (OptEIATM; BD Biosciences - Pharmingen).

CNS leukocyte infiltration. Leukocytes were isolated from the CNS as described previously (55). The total number of $\mathrm{CD} 45^{\text {high }}, \mathrm{CD} 11 \mathrm{~b}^{+}, \mathrm{CD}^{+}$, and $\mathrm{CD}^{+} \mathrm{T}$ cells in the CNS was assessed by flow cytometry, using a fixed number of latex beads (Beckman Coulter) coacquired with a preestablished volume of the cellular suspensions.

$D C s$. Bone marrow from naive mice was flushed, and single-cell suspensions were cultured $\left(37^{\circ} \mathrm{C} ; 5 \% \mathrm{CO}_{2}, 95 \%\right.$ humidity) in RPMI 1640 (Invitrogen), $2 \mathrm{mM}$ L-glutamine (Sigma-Aldrich), $100 \mathrm{U} / \mathrm{ml}$ penicillin, $100 \mu \mathrm{g} / \mathrm{ml}$ streptomycin (all from Invitrogen), and 1\% GM-CSF conditioned medium. Medium was replaced every 48 hours until day 6 of culture, after which CD11c cells were purified as described above or remained untreated.
EAE induction and protoporphyrin treatment. Briefly, C57BL/6 and SJL/J mice were immunized subcutaneously with $\mathrm{MOG}_{35-55}$ or $\mathrm{PLP}_{139-151}(200$ $\mu \mathrm{g})$, respectively, emulsified in CFA (BD Diagnostics) supplemented with Mycobacterium tuberculosis (400 $\mu \mathrm{g}$; BD Diagnostics). C57BL/6 mice received Pertussis toxin (200 ng i.v.; Sigma-Aldrich) at the time of immunization and 2 days thereafter. Clinical signs of EAE were evaluated daily and scored as follows: 0 , normal; 1 , limp tail; 2 , partial paralysis of the hind limbs; 3 , complete paralysis of the hind limbs; 4 , hind-limb paralysis and forelimb weakness; 5 , moribund or deceased. Protoporphyrins were administered daily $(200 \mu \mathrm{l}$ i.p., $5 \mathrm{mg} / \mathrm{kg}$ ). Biliverdin was administered at $5 \mu \mathrm{M} / \mathrm{kg}$ every 12 hours.

Flow cytometry and antibodies. Surface markers and intracellular cytokines were detected essentially as described previously (55). Purified anti-mouse CD4 (RM4-5), CD8 (YTS169.4), CD11b (M1/70), CD11c (HL3), CD40 (3/23), CD45 (30-F11), CD80 (16-10A1), CD86 (GL1), B220 (RA3-6B2), I-A ${ }^{\mathrm{b}}$ (AF6-120.1), IL-2 (JES6-5H4), IL-10 (JES5-16E3), TNF- $\alpha$ (MP6-XT22), and IFN- $\gamma$ (XMG1.2; all BD Biosciences - Pharmingen) were used. Anti-Fc $\gamma$ III/II receptor mAbs were prepared in house from hybridoma (2.4G2) culture supernatants. Antibodies were directly conjugated to PE, allophycocyanin, or FITC.

In vivo BrdU incorporation. Mice received $\mathrm{BrdU}(50 \mu \mathrm{g} / \mathrm{g}$ body weight i.p. administered 4 times every 2 hours; BD Biosciences - Pharmingen). CNS leukocyte infiltrates were isolated as described above, and nuclear BrdU was detected using the FITC-labeled anti-BrdU Flow Kit according to the manufacturer's indications (BD Biosciences - Pharmingen).

Leukocyte isolation and purification. Draining lymph nodes were homogenized into single-cell suspension. $\mathrm{CD}^{+}$and $\mathrm{CD} 11 \mathrm{c}^{+}$cells were purified using single-step anti-CD4 (L3T4) and anti-CD11c (N418) MicroBeads, respectively (Miltenyi Biotec). $\mathrm{CD}^{+}$and $\mathrm{CD} 19^{+}$cells were purified by 2-step labeling consisting of FITC-labeled anti-CD8 (SK1) and anti-CD19 (4G7) $\mathrm{mAb}(\mathrm{BD})$ followed by anti-FITC-conjugated MicroBeads (Miltenyi Biotec). Cells were separated using a MidiMACS magnetic isolation system (Miltenyi Biotec), and purity was assessed by flow cytometry.

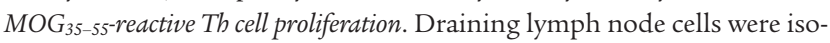
lated from PBS-, CoPPIX-, or ZnPPIX-treated animals 8 days after footpad immunization ( $\mathrm{MOG}_{35-55}$ plus $\mathrm{CFA}$ ). Cells were plated in 96-well microtiter plates $\left(5 \times 10^{5}\right.$ cells per well) in RPMI 1640 (Invitrogen), $2 \mathrm{mM}$ L-glutamine (Sigma-Aldrich), $100 \mathrm{U} / \mathrm{ml}$ penicillin, $100 \mu \mathrm{g} / \mathrm{ml}$ streptomycin, $10 \%$ FCS, $50 \mu \mathrm{M}$ 2-mercaptoethanol (2-ME), $10 \mathrm{mM}$ HEPES, and $1 \mathrm{mM}$ sodium pyruvate (all from Invitrogen) and exposed to $\mathrm{MOG}_{35-55}(10 \mu \mathrm{g} / \mathrm{ml})$ or concanavalin A ( $2 \mu \mathrm{g} / \mathrm{ml}$; Sigma-Aldrich) for 72 hours at $37^{\circ} \mathrm{C}\left(5 \% \mathrm{CO}_{2}, 95 \%\right.$ humidity). Cell proliferation was assessed by $\left[{ }^{3} \mathrm{H}\right]$ thymidine $(1 \mu \mathrm{Ci} /$ well; GE HealthCare) incorporation during the last 6 hours of culture evaluated in a scintillation counter (Tomtec; Pharmacia).

Immunocytochemistry. Purified bone marrow-derived DCs were plated in glass coverslips (Paul Marienfeld $\mathrm{GmbH} \& \mathrm{Co}$.) and fixed in acetone $\left(10\right.$ minutes at $\left.-20^{\circ} \mathrm{C}\right)$. Rabbit anti-HO-1 polyclonal antibody (SPA895; Stressgene Biotechnologies), PE-labeled anti-CD11c mAb (HL3; BD Biosciences - Pharmingen) and FITC-labeled goat anti-rabbit polyclonal antibody (Sigma-Aldrich) were used. Slides were mounted in VECTASHIELD (Vector Laboratories), and fluorescence was detected by confocal microscopy (Leica Spectral TCS-SP2; Leica Microsystems). Images were acquired using Leica confocal software (version 2.61).

Histology. Mice were perfused with PBS followed by $10 \%$ formalin. Brain and spinal cord sections were embedded in paraffin and stained with hematoxylin and eosin or with Luxol fast blue stains, and inflammatory foci were enumerated in meninges and parenchyma as described previously (56).

Immunohistology. Mice were perfused with PBS, and their spinal cords were harvested, embedded in Tissue-Tek OCT (Sakura), and snap-frozen in liquid nitrogen. Spinal cord sections $(10 \mu \mathrm{m})$ were fixed in acetone, and antigen detection was performed essentially as described previously (47). 
Rabbit anti-HO-1 polyclonal antibody (SPA895; Stressgene Biotechnologies), biotin-labeled anti-MHC class II mAb (AF6-120.1; BD Biosciences - Pharmingen), PE-labeled anti-CD11c mAb (HL3; BD Biosciences Pharmingen), and FITC-labeled goat anti-rabbit (Sigma-Aldrich) polyclonal antibody were used. HRP-conjugated streptavidin and VECTASTAIN Elite $\mathrm{ABC}$ kit were used according to the manufacturer's instructions (Vector Laboratories). HRP stainings were revealed using 3,3-diamenobenzidine (Sigma-Aldrich), and tissues were counterstained with Harris hematoxylin (Sigma-Aldrich). Images were acquired using a Leica (DM.LB2) microscope (Leica Microsystems) equipped with an Evolution MP5.0 color camera (MediaCybernetics) and free-GIMP 2.2.10 software (http://portableapps. com/apps/graphics_pictures/gimp_portable). Fluorescence staining was detected and processed as described above.

CO exposure. Mice were placed in a plexiglass gastight 60-1 capacity chamber and exposed continuously to $\mathrm{CO}$ as described previously (47). Cells $\left(37^{\circ} \mathrm{C}, 95 \%\right.$ humidity) were exposed to $\mathrm{CO}\left(250 \mathrm{ppm}\right.$ in air, $\left.5 \% \mathrm{CO}_{2}\right)$ in a plexiglass gastight $10-1$ chamber $(2 \mathrm{l} / \mathrm{min})$. CO concentration was monitored using a $\mathrm{CO}$ analyzer (Interscan Corporation). Air controls were maintained in a similar chamber without $\mathrm{CO}$.

Western blots and antibodies. Western blots were performed as described previously $(46,47)$ using anti-HO-1 (SPA896; Stressgene Biotechnologies), anti-STAT-1 (Upstate USA Inc.), and anti-phospho-STAT-1 (Upstate USA Inc.) rabbit polyclonal antibodies as well as anti- $\beta$-tubulin (Sigma-Aldrich) and anti- $\beta$-actin (Sigma-Aldrich) mouse mAbs. HRP-labeled goat anti-rabbit (31460; Pierce Biotechnology) or goat anti-mouse (31439; Pierce Biotechnology) polyclonal antibodies were used to detect the primary antibodies. HRP activity was revealed using ECL. Images were acquired using a Kodak 440CF image station.

Real-time PCR. Total RNA was extracted using RNeasy Protect Mini Kit (QIAGEN) according to the manufacturer's instructions and reverse transcribed as described previously (22). HO-1 (5'-TCTCAGGGGGTCAGGTC-3' and 5'-GGAGCGGTGTCTGGGATG-3'), CIITA (5'-CTCTACCACCTCTATGACC- $3^{\prime}$ and $5^{\prime}$-GCTTCTGTCCTGCTTCTAC- $3^{\prime}$ ), and hypoxanthine-guanine phosphoribosyl transferase (HPRT; 5'-GTT-
GGATACAGGCCAGACTTTGTTG-3' and 5'-GATTCAACCTTGCGCTCATCTTAGGC-3') PCR products were detected using LightCycler realtime quantitative PCR (Roche Diagnostics) as described previously (22).

Statistics. Significance of clinical scores significance was examined by the Mann-Whitney test. Significance of $\mathrm{Hmox}^{1^{-/-}}$versus $\mathrm{Hmox} \mathrm{1}^{+/+}$mouse survival was examined by the log-rank test. Fisher's exact test was used for analyses of disease remission. All other statistical analyses were performed using ANOVA with Bonferroni's correction for multiple comparisons. $P<0.05$ was considered significant in all tests.

\section{Acknowledgments}

This work was supported primarily by a GEMI Fund AgaLinde Healthcare grant to M. Soares. Â. Chora, A. Cunha, and T.F. Pais were supported by fellowships BD/3106/2000, SFRH/ $\mathrm{BD} / 21558 / 2005$, and SFRH/BPD/5554/2001, respectively, from Fundação para a Ciência e Tecnologia. R.A. Sobel was supported by NIH grant NS 046414. The authors thank Abdel Saoudi (Institut National de la Sante et de la Recherche Medicale) for essential input at the initial phase of this project and Fritz H. Bach (Harvard Medical School), Jocelyne Demengeot (Instituto Gulbenkian de Ciência), and Santiago Zelenay (Instituto Gulbenkian de Ciência) for critical reading of the manuscript. We also wish to thank Nuno Sepúlveda and Ana Cristina Paulo for support with statistical analysis, Sofia Rebelo for excellent technical support, António Sousa for building the $\mathrm{CO}$ exposure chambers, and Mark P. Seldon for setting up and advising with $\mathrm{CO}$ exposure.

Received for publication April 17, 2006, and accepted in revised form November 28, 2006.

Address correspondence to: Miguel Soares, Instituto Gulbenkian de Ciência, Rua da Quinta Grande, 6, 2780-156 Oeiras, Portugal. Phone: 351-214464520; Fax: 351-214407970; E-mail: mpsoares@ igc.gulbenkian.pt.
1. Noseworthy, J.H., Lucchinetti, C., Rodriguez, M., and Weinshenker, B.G. 2000. Multiple sclerosis. N. Engl. J. Med. 343:938-952.

2. Hafler, D.A. 2004. Multiple sclerosis. J. Clin. Invest. 113:788-794. doi:10.1172/JCI200421357.

3. Hemmer, B., Archelos, J.J., and Hartung, H.P. 2002. New concepts in the immunopathogenesis of multiple sclerosis. Nat. Rev. Neurosci. 3:291-301.

4. Steinman, L. 2001. Multiple sclerosis: a two-stage disease. Nat. Immunol. 2:762-764.

5. Nathan, C. 2002. Points of control in inflammation. Nature. 420:846-852.

6. Lafaille, J.J., Nagashima, K., Katsuki, M., and Tonegawa, S. 1994. High incidence of spontaneous autoimmune encephalomyelitis in immunodeficient anti-myelin basic protein $\mathrm{T}$ cell receptor transgenic mice. Cell. 78:399-408.

7. Bach, F.H., Hancock, W.W., and Ferran, C. 1997. Protective genes expressed in endothelial cells: a regulatory response to injury. Immunol. Today. 18:483-486.

8. Otterbein, L.E., Soares, M.P., Yamashita, K., and Bach, F.H. 2003. Heme oxygenase-1: unleashing the protective properties of heme. Trends Immunol. 24:449-455.

9. Schipper, H.M. 2004. Heme oxygenase expression in human central nervous system disorders. Free Radic. Biol. Med. 37:1995-2011.

10. Schluesener, H.J., and Seid, K. 2000. Heme oxygenase- 1 in lesions of rat experimental autoimmune encephalomyelitis and neuritis. J. Neuroimmunol. 110:114-120.

11. Steinman, L., and Zamvil, S.S. 2005. Virtues and pitfalls of EAE for the development of therapies for multiple sclerosis. Trends Immunol. 26:565-571.

12. Tenhunen, R., Marver, H.S., and Schmid, R. 1968. The enzymatic conversion of heme to bilirubin by microsomal heme oxygenase. Proc. Natl. Acad. Sci. U. S. A. 61:748-755.

13. Ryter, S.W., and Tyrrell, R.M. 2000. The heme synthesis and degradation pathways: role in oxidant sensitivity. Heme oxygenase has both proand antioxidant properties. Free Radic. Biol. Med. 28:289-309.

14. Wagener, F.A., et al. 2003. Different faces of the heme-heme oxygenase system in inflammation. Pharmacol. Rev. 55:551-571.

15. Kim, H.P., Ryter, S.W., and Choi, A.M. 2005. CO as a cellular signaling molecule. Annu. Rev. Pharmacol. Toxicol. 46:411-449.

16. Ollinger, R., et al. 2005. Bilirubin: a natural inhibitor of vascular smooth muscle cell proliferation. Circulation. 112:1030-1039.

17. Eisenstein, R.S., Garcia, M.D., Pettingell, W., and Munro, H.N. 1991. Regulation of ferritin and heme oxygenase synthesis in rat fibroblasts by different forms of iron. Proc. Natl. Acad. Sci. U. S. A. 88:688-692.

18. Ferris, C., et al. 1999. Haem oxygenase-1 prevents cell death by regulating cellular iron. Nat. Cell Biol. 1:152-157.

19. Liu, Y., et al. 2001. Heme oxygenase- 1 plays an important protective role in experimental autoimmune encephalomyelitis. Neuroreport. 12:1841-1845.

20. Chakrabarty, A., Emerson, M.R., and LeVine, S.M.
2003. Heme oxygenase-1 in SJL mice with experimental allergic encephalomyelitis. Mult. Scler. 9:372-381.

21. Sato, K., et al. 2001. Carbon monoxide generated by heme oxygenase- 1 suppresses the rejection of mouse to rat cardiac transplants. J. Immunol. 166:4185-4194.

22. McDaid, J., et al. 2005. Heme oxygenase-1 modulates the allo-immune response by promoting activation-induced cell death of $\mathrm{T}$ cells. FASEB J. 19:458-460.

23. Pae, H.O., et al. 2004. Carbon monoxide produced by heme oxygenase- 1 suppresses $\mathrm{T}$ cell proliferation via inhibition of IL-2 production. J. Immunol. 172:4744-4751.

24. Chauveau, C., et al. 2005. Heme oxygenase-1 expression inhibits dendritic cell maturation and pro-inflammatory function but conserves IL-10 expression. Blood. 106:1694-1702.

25. Appleton, S.D., et al. 1999. Selective inhibition of heme oxygenase, without inhibition of nitric oxide synthase or soluble guanylyl cyclase, by metalloporphyrins at low concentrations. Drug Metab. Dispos. 27:1214-1219.

26. Heppner, F.L., et al. 2005. Experimental autoimmune encephalomyelitis repressed by microglial paralysis. Nat. Med. 11:146-152.

27. Greter, M., et al. 2005. Dendritic cells permit immune invasion of the CNS in an animal model of multiple sclerosis. Nat. Med. 11:328-334.

28. Chang, C.H., Guerder, S., Hong, S.C., van Ewijk, W., and Flavell, R.A. 1996. Mice lacking the MHC class II transactivator (CIITA) show tissue-specific 
impairment of MHC class II expression. Immunity. 4:167-178.

29. Reith, W., LeibundGut-Landmann, S., and Waldburger, J.M. 2005. Regulation of MHC class II gene expression by the class II transactivator. Nat. Rev. Immunol. 5:793-806.

30. Yamashita, K., et al. 2004. Biliverdin, a natural product of heme catabolism, induces tolerance to cardiac allografts. FASEB J. 18:765-767.

31. Stuve, O., et al. 2002. The role of the MHC class II transactivator in class II expression and antigen presentation by astrocytes and in susceptibility to central nervous system autoimmune disease. J. Immunol. 169:6720-6732.

32. Ponomarev, E.D., Shriver, L.P., Maresz, K., and Dittel, B.N. 2005. Microglial cell activation and proliferation precedes the onset of CNS autoimmunity. J. Neurosci. Res. 81:374-389.

33. Becher, B., Bechmann, I., and Greter, M. 2006. Antigen presentation in autoimmunity and CNS inflammation: how $\mathrm{T}$ lymphocytes recognize the brain. J. Mol. Med. 84:532-543.

34. Sospedra, M., and Martin, R. 2005. Immunology of multiple sclerosis. Annu. Rev. Immunol. 23:683-747.

35. Kuchroo, V.K., et al. 1994. A single TCR antagonist peptide inhibits experimental allergic encephalomyelitis mediated by a diverse $\mathrm{T}$ cell repertoire. J. Immunol. 153:3326-3336.

36. Olivares-Villagomez, D., Wang, Y., and Lafaille, J.J. 1998. Regulatory CD4(+) T cells expressing endogenous $T$ cell receptor chains protect myelin basic protein-specific transgenic mice from spontaneous autoimmune encephalomyelitis. J. Exp. Med. 188:1883-1894.

37. Kohm, A.P., Carpentier, P.A., Anger, H.A., and Miller, S.D. 2002. Cutting edge: $\mathrm{CD} 4+\mathrm{CD} 25+$ regulatory $\mathrm{T}$ cells suppress antigen-specific autoreactive immune responses and central nervous system inflammation during active experimental autoimmune encephalomyelitis. J. Immunol. 169:4712-4716.

38. Hori, S., Haury, M., Coutinho, A., and Demengeot, J. 2002. Specificity requirements for selection and effector functions of CD25+4+ regulatory T cells in anti-myelin basic protein $\mathrm{T}$ cell receptor transgenic mice. Proc. Natl. Acad. Sci. U. S. A. 99:8213-8218.

39. Brusko, T.M., Wasserfall, C.H., Agarwal, A., Kapturczak, M.H., and Atkinson, M.A. 2005. An integral role for heme oxygenase- 1 and carbon monoxide in maintaining peripheral tolerance by CD $4+C D 25+$ regulatory T cells. J. Immunol. 174:5181-5186.

40. Zelenay, S., Chora, A., Soares, M.P., and Demengeot, J. 2006. Heme oxygenase- 1 is not required for mouse regulatory $\mathrm{T}$ cell development and function. Int. Immunol. 19:11-18.

41. Bettelli, E., et al. 1998. IL-10 is critical in the regulation of autoimmune encephalomyelitis as demonstrated by studies of IL-10- and IL-4-deficient and transgenic mice. J. Immunol. 161:3299-3306.

42. Liu, J., et al. 1998. TNF is a potent anti-inflammatory cytokine in autoimmune-mediated demyelination. Nat. Med. 4:78-83.

43. Butovsky, O., et al. 2006. Induction and blockage of oligodendrogenesis by differently activated microglia in an animal model of multiple sclerosis. J. Clin. Invest. 116:905-915. doi:10.1172/JCI26836.

44. Panitch, H.S., Hirsch, R.L., Haley, A.S., and Johnson, K.P. 1987. Exacerbations of multiple sclerosis in patients treated with gamma interferon. Lancet. 1:893-895.

45. Chu, C.Q., Wittmer, S., and Dalton, D.K. 2000. Failure to suppress the expansion of the activated CD4 $\mathrm{T}$ cell population in interferon gamma-deficient mice leads to exacerbation of experimental autoimmune encephalomyelitis. J. Exp. Med. 192:123-128.

46. Brouard, S., et al. 2000. Carbon monoxide generated by heme oxygenase 1 suppresses endothelial cell apoptosis. J. Exp. Med. 192:1015-1026.

47. Otterbein, L.E., et al. 2000. Carbon monoxide has anti-inflammatory effects involving the mitogen-activated protein kinase pathway. Nat. Med. 6:422-428.

48. Bishop, A., Yet, S.F., Lee, M.E., Perrella, M.A., and Demple, B. 2004. A key role for heme oxygenase-1 in nitric oxide resistance in murine motor neurons and glia. Biochem. Biophys. Res. Commun. 325:3-9.

49. Hovelmeyer, N., et al. 2005. Apoptosis of oligodendrocytes via Fas and TNF-R1 is a key event in the induction of experimental autoimmune encephalomyelitis. J. Immunol. 175:5875-5884.

50. Soares, M.P., et al. 1998. Expression of heme oxygenase- 1 can determine cardiac xenograft survival. Nat. Med. 4:1073-1077.

51. Yachie, A., et al. 1999. Oxidative stress causes enhanced endothelial cell injury in human heme oxygenase-1 deficiency. J. Clin. Invest. 103:129-135.

52. Exner, M., Minar, E., Wagner, O., and Schillinger, M. 2004. The role of heme oxygenase- 1 promoter polymorphisms in human disease. Free Radic. Biol. Med. 37:1097-1104.

53. Yet, S.F., et al. 1999. Hypoxia induces severe right ventricular dilatation and infarction in heme oxygenase-1 null mice. J. Clin. Invest. 103:R23-R29.

54. Blasi, E., Barluzzi, R., Bocchini, V., Mazzolla, R., and Bistoni, F. 1990. Immortalization of murine microglial cells by a v-raf/v-myc carrying retrovirus. J. Neuroimmunol. 27:229-237.

55. Pais, T.F., and Chatterjee, S. 2005. Brain macrophage activation in murine cerebral malaria precedes accumulation of leukocytes and CD8+ T cell proliferation. J. Neuroimmunol. 163:73-83.

56. Fontoura, P., et al. 2004. Immunity to the extracellular domain of Nogo-A modulates experimental autoimmune encephalomyelitis. J. Immunol. 173:6981-6992. 